\title{
Subscribing to WII-FM: When will we Begin to Function as a Team?
}

\section{Dr. Andrew E. Jackson, East Carolina University}

Dr. Jackson serves as a Tenured, Full Professor in the Department of Technology Systems at ECU. He is a senior faculty member in the Industrial Engineering Technology (IET) program where he teaches a variety of IET courses, including: Production Systems Engineering and Production Planning, Engineering Economics, Human Factors Engineering, and Risk Assessment. His career spans 40 years in the fields of aviation, aerospace, defense contract engineering support, systems acquisition, academics, and systems engineering.

\section{Dr. Sherion H Jackson, Grand Canyon Univeristy}

Sherion is a native Texan who currently makes her home in Eastern North Carolina. She earned her doctorate in Educational Leadership and Supervision from Arizona State University, and her BS in Liberal Studies and MA in Elementary Education, both from the University of Central Florida. In the role of educator over the past 30+ years, she has served as associate professor, online facilitator, educational consultant, SACS Reviewer, mentor, school superintendent, school principal, and elementary teacher for various school districts and universities across the United States. Her experience in higher education consists of scholarship, administrative responsibilities, and facilitation of graduate and undergraduate level courses using several, unique online learning platforms and face-to-face delivery methods. Sherion truly enjoys working with adults in the online learning environment. She has facilitated over 100 online graduate level classes and authored or co-authored more than 30 journal articles. 


\title{
Subscribing to WII-FM: When will we Begin to Function as a Team?
}

\begin{abstract}
Teams are utilized in a variety of ways, covering a wide range of organizational functions. Most working professionals have been asked to serve on a team at one time or another. If not, the likelihood that they will be asked to do so in at some time during their career is extremely high. Why is this true? First - and foremost - teams have been shown to flesh out more relevant issues more quickly and more thoroughly than any one individual can typically generate on his or her own. This fundamental assumption leads to the development of teams to address almost every conceivable topic and in every recognizable domain. However, some fundamental questions have plagued managers for years (if not for centuries). What if the team does not want to work together? - or - What if they merely do not know how to work together? This is where an understanding of group dynamics, team organizational, and communication skills come into play.

Students and faculty face a particularly difficult task when working in academic team environments. Most students realize that several artificial constraints are in play for these studentcentered projects. These artificial elements include - but are not limited to: 1) the short-term nature of the team assignments, 2) the final objective of the project assignment [usually a report or an artificial product] which is generally never developed into a sustainable design or functional product that will ultimately be manufactured, distributed, and maintained throughout a typical lifecycle, 3 ) the low probability that their individual long-term success is dependent on other members of the student team, 4) the student's ability to remain in the background and let other team members do the bulk of the work knowing that they will likely receive the same benefit (or project grade) in the end, and 5) the low probability that any long-term, adverse effects will result if they do the minimum amount of work in their respective team . . . i.e. doing just enough work to get through the course. This situation may result in a WII-FM or What's In It For Me philosophy by team members.
\end{abstract}

This paper will address several team-related components that affect student success in both faceto-face (F2F) courses and in Distance Education (DE) courses and provide a template for faculty to use to address these issues. Similarities and differences in team effectiveness using F2F and DE delivery methodologies will also be addressed. Both synchronous and asynchronous DE course models will be discussed.

Introduction

Tell me and I'll forget; show me and I may remember; involve me and I'll understand. (Letassy, Fugate, Medina, Stroup, \& Britton, 2008) ${ }^{8}$.

The above quotation is a Chinese proverb noted in a journal article by Letassy, et al. (2008) ${ }^{8}$ with the objective of proving that team-based learning (TBL) is an effective way of teaching students, 
getting them involved, and providing experiences to base their understanding upon. Teams are required in most work environments to do problem solving and to glean ideas from all of the employees. A team is defined as a group of people working together for a common goal (Barkley $\&$ Saylor, 2001) ${ }^{1}$. Teams share responsibility and are empowered to get work done. When students are given tasks as members of team, they are given the opportunity to learn from the experiences of the other team members. Effective teams learn how to use diversity and creativity of all team members to their best advantage. Teams should accept "ownership" of the team performance and take pride in it. Working in teams promotes active learning and makes the learning experience more fun. Teams give students the opportunity to work with students from all walks of life. The majority of Distance Education (DE) students are of mature age, working in industry, with a significant base of practical, industry, and life skills (Brodie, 2009) ${ }^{3}$. On campus students are usually younger and have more traditional academic skills such as math, physics, computer, etc. Bringing these two groups together into teams provides a unique opportunity for learning and sharing.

The challenge is how to do this effectively. There are few instructors who do more than assign teams (Vik, 2001) ${ }^{12}$. Effective teams need to be trained to work in teams. They need to be taught the various stages of team development. The reality of it is that there will be issues. There will even be times when teams have to "fire" team members. Frequent faculty feedback is absolutely essential for teams to work effectively. Other issues that need to be taught are: how to handle successes and failures and how to use peer evaluations to improve teamwork (Vik, 2001) ${ }^{12}$.

What is teamwork?

Teamwork is a technique that allows individual team members to work together to achieve a common goal (Barkley \& Saylor, 2001) ${ }^{1}$. In their gook entitled: Customer-Driven Project Management, Barkley and Saylor spell out teamwork as specifically involving the following attributes:

- Trust

- $\quad$ Effective communication, especially listening

- $\quad$ A positive "can do " attitude

- $\quad$ Motivation to perform and improve

- "We" mentality

- "Ownership" of work with pride

- $\quad$ Respect and consideration of others

- $\quad$ Keeping focus on total customer satisfaction (from the student's perspective, this equates to the instructor's satisfaction)

In a team, the members must decide among themselves who will do the what, where, when, and how of work. 
Why form teams? What's in it for me (WII-FM)?

According to Muchinsky (2006) ${ }^{9}$, there are three critical factors that require the creation of teams in the contemporary world of work and school. The first is the extreme amount of information and knowledge that is in existence. Society has entered the Information Age. It is absolutely impossible for one person to have technical expertise in all areas of knowledge. Therefore, a team approach draws on a resource of knowledge from people in various degrees of expertise. Secondly, the working population is becoming more educated and trained. Years ago, the workforce was relatively uneducated. Very few people even achieved a high school diploma, much less a college education. In those days people were monitored by managers who had the higher levels of education and training. Today, employers require their employees to have the level of education to be able to manage their own work environment. As one worker stated: "I'm no longer expected to check my brain at the front gate when I enter the factory" (Muchinsky, 2006, p. 286) ${ }^{9}$. The third factor requiring the forming of teams is the rate of change in work activities. For many years workers had well-defined work activities in their jobs that rarely ever changed (Muchinsky, 2006) ${ }^{9}$. Today work activities rarely ever stay the same. Work teams can be adaptable to these ever-changing work conditions. In order to be prepared to work in these types of environments, students must be taught how to work in teams and what to expect when working with team members.

Teams also make a big difference in the motivation of students and impacts the learning outcomes. An article by Gomez, Wu, and Passerini (2010) ${ }^{6}$ published in the Computers and Education Journal emphasized computer-based team learning (CS-TBL). The work extended from learning in small teams in the traditional classroom to the hybrid classroom where students met both face-to-face and online with an emphasis on team building. At the end of the study, students were given evaluations to determine the quality of perceived learning, perceived motivation, perceived enjoyment, and perceived team member's valuable contributions. The majority of students who were evaluated logged scores in the categories of agree or strongly agree. Eighty-six percent (86\%) of the students evaluated said that they enjoyed sharing their knowledge of course related materials with their teams through CS-TBL (Gomez, Wu, \& Passerini, 2010) ${ }^{6}$.

In a work situation, empowering employees to make decisions without constraining them, shows the highest level of trust (Evans \& Lindsay, 2008) ${ }^{5}$. The same applies to student-instructor relationships. Empowering students to work in a team environment gives them a high level of trust from the instructors. It encourages the team members to work together to tackle the tasks at hand. This type of training more readily prepares students for the reality of the workforce.

The stages of team development

Tuckman $(1965)^{10}$ identified four stages of group dynamics and has classified these four stages as: Forming, Storming, Norming, and Performing. Tuckman \& Jensen $(1977)^{11}$ added a new 
dimension to Tuckman's original model by including a fifth step called Mourning (or Reforming). To establish and maintain a productive team atmosphere, the leader of the team, or another manager who may be outside of the group structure altogether, must monitor the dynamics and inter-personal relationships that are occurring within the team. The important element is to move through the Forming, Storming, and Norming phases as quickly and as efficiently as possible so the participants can begin the real work assigned to the team which resides in the Performance arena, leading to closure of the project during the Adjourning stage.

Groups or teams tend to go through a number of phases or stages if the teams exist for an extended period. Tuckman (1965) ${ }^{10}$ describes the process of going through four stages entitled: Forming, Storming, Norming, and Performing. Given the length of a semester, students must go through the first three stages quite rapidly in order to reach the final desired stage of Performing.

Forming stage

In the Forming stage, students learn about each other and the task at hand. This is a comfortable stage to be in, but very little gets done. This is also the stage when the members establish relationships with leaders, organizational standards, and with each other (Bonebright, 2010) ${ }^{2}$.

Storming stage

The second stage of Storming is when the teams start to address issues and minor (or major) confrontations can arise. This stage is characterized by a lack of unity and polarization around interpersonal issues (Bonebright, 2010) ${ }^{2}$. It is important to have structural clarity and ground rules. This is the stage that students most need to be taught how to handle differences of opinion and variations in each team member's techniques and what to expect from each other as the project activities are addressed.

\section{Norming stage}

In the Norming stage, the students should get past the arguments to set rules for how the scope of the task is to be accomplished. The group starts to develop cohesion (Bonebright, 2010) ${ }^{2}$. Rules are established which help define how the group will address and resolve differences of opinion. These rules are designed to minimize interpersonal conflicts without alienating one or more team members in the process. Task conflicts should be avoided in this stage to retain harmony in the group. Compromise and consensus are two of the primary outcomes of an effective team as the Norming Stage is implemented.

Performing stage

In the final stage of the original model, the group develops 'functional role relatedness' (Tuckman, 1965, p. 389) ${ }^{10}$. The group becomes a "problem-solving instrument" (Bonebright, 2010, p. 114) $)^{2}$. Roles become more flexible and the team is ready to move on with solving the tasks at hand. Task or mission accomplishment - as defined by the manager (or the instructor) - is 
the desired outcome for each assigned team. The Performing Stage is the only phase where progress toward as shared objective can be witnessed. Once the team members recognize the four phases of team development as defined by Tuckman ${ }^{10,11}$ and others, they are better able to maintain a group identity and move toward successful completion of the assigned tasks.

Equitable assessment of team member's contributions

Fortunately, most students who enroll in higher education courses recognize their shared time constraints - as defined by the course schedule or by the instructor, so most teams tend to work together to define the scope of their project and divide the project tasks appropriately. However, some student teams or team members tend to procrastinate and attempt to push their assigned responsibilities onto their peers. This factor causes additional stress within the teams and often leads to poor quality and inadequate scope or quality for the final project activities. In an operational setting, the differential level or quality of any team member's contributions must be recognized and documented by the project sponsor (or instructor) in order to assess the individual contributions of team members within a group setting.

Jackson (2005) ${ }^{7}$ introduced a group performance/assessment tool for use in academic settings. A Peer Evaluation Tool was created for student team members to provide feedback about their contributions to the team effort. Each individual also provides a fair and accurate assessment for every other member of their team. Once the final project files are submitted each semester, each team member is required to assign points for their individual effort and for each of their team member's efforts throughout the project. Originally these peer evaluations were merely used for feedback purposes to the instructor, but over time, it became clear that some team members were not contributing their fair share to the required project activities, therefore, based on their contribution to the final product(s), the author felt that these students should not receive the same grade on the project deliverables as other high-performing members of the project team. Within the past year, the results of the required Peer Evaluations are now being incorporated directly into the grading structure for the project.

In order to assess the quality and scope of each team member's efforts within the project, students are asked to provide a fair and equitable assessment of their team's performance. Once the Peer Evaluation scores have been compiled, the instructor can determine who has contributed more than expected, compared to those individuals who have demonstrated marginal (or no) performance on team activities. For those team members who participated equally throughout the semester, Peer Evaluation scores almost always reflect equal scores for all team participants, therefore - based on the team members' collective assessments - no grade advantage or grade penalty is required for any of the team members. By dividing the individual student's Peer Evaluation assessment by the base score available within the Peer Evaluation tool, a multiplier is identified. In this case all team members will have a multiplier of 1.0 (or very near 1.0) therefore they would receive the same grades for all project deliverables within the course. 
For those team members who clearly carry more than their fair share of the project load, their cumulative peer evaluations tend to be higher than for team members who contributed less than their fair share throughout the project. In this situation, team-based assessments provide high performing team members with a higher cumulative Peer Evaluation score than some of their team members. This multiplier would be greater than 1.0 which could then be used to adjust the baseline project grades as needed to reflect the quality of one or more team member's contributions. Similarly, for underperforming student team members, the Peer Evaluation multiplier would be less than 1.0, thus leading to a lower project score than other team members within the project team. This project team assessment model more accurately reflects the individual's contributions to the team effort throughout the semester.

Adjourning, mourning, or reforming stage

In 1977, Tuckman \& Jensen ${ }^{11}$ added a fifth stage to the original Tuckman model to include an Adjourning stage. This stage has also been described as the Mourning or Reforming stage where a team is disbanded or reassigned after completing their assigned tasks. This condition may also be apparent when one or more new members are added to the existing team or when one or more current members are removed from the team. In this stage team members suffer some anxiety about separation from the other team members (Tuckman \& Jensen, 1977) ${ }^{11}$. Teams often fear what is going to happen in the future without the aid of their other team members.

Distance education (DE) versus face-to-face (F2F) course teamwork

DE students differ from F2F students in that they rarely have the opportunity to meet each other across the table. Reducing or eliminating F2F contact in team settings effectively creates a disconnect between the traditional verbal and visual communications model that we have grown up with and a "text-only" communications model used in most virtual communications models. While it is true that technology is constantly evolving, which may provide more effective face-toface communications capabilities over time, student teams will not always have access to newer on-line communications technologies, thus continuing to limit their ability to engage in virtual F2F meetings. A non-visual communication model tends to limit people's ability to communicate effectively. When we are not able to see the individual who we are trying to communicate with, several critical communications cues are missing. Nonverbal cues, body language, tone, inflection, and context, and common language models are used during any team's communications.

Effective communication is the basic foundation which determines the success of any small group or team (Chaparro, Langrall, Malzahn, Mohler, Russell, \& Whitman, 2005) ${ }^{4}$. Without the F2F interaction, communication can be difficult. A study was conducted by a large Midwestern university using students in a F2F environment and students in a computer-mediated distance education environment. Both F2F and DE students were divided up into teams for the study. The course studied was a lean manufacturing course designed to include practical learning for 
graduate students (Chaparro, et al., 2005) ${ }^{4}$. Students in both the F2F and DE were asked to create a value stream map using the Blackboard ${ }^{\mathrm{TM}}$ course management system.

Students were compared by final project grades, attitudes and reactions to group processes, and overall satisfaction with the team building experience. In the end, there was no statistically significant difference between the final project scores in the F2F and the DE students. There was, however, a variance in the project scores between the two. The F2F group scored higher in the project scores. The aim of the study was to compare the final project scores between the two groups. It was determined that the lower scores of the DE group indicated that the groups were new to the technology and found the experience to be challenging. Table 1 lists some of the things F2F students in the study and DE or Computer-Mediated Class (CMC) students liked most about the team concept (Chaparro, et al., 2005) ${ }^{4}$.

Table 1.

F2F versus CMC: Sources of satisfaction with their team experience (Chaparro, et al., 2005) ${ }^{4}$

\begin{tabular}{|c|c|}
\hline Face-to-Face & Computer-Mediated Classes (CMC) \\
\hline What Teams Liked Most & What Teams Liked Most \\
\hline $\begin{array}{l}\text { - It helped me to understand problems to } \\
\text { be in a group. In the future, this will } \\
\text { help me to attend, and participate in } \\
\text { group meetings more effectively. } \\
\text { - The group was easy to work with. } \\
\text { Everyone was engaged and intelligent } \\
\text { in approaching the problems. } \\
\text { - Coming together and providing each } \\
\text { and everybody's ideas and } \\
\text { brainstorming } \\
\text { - Sharing of ideas and innovative } \\
\text { thinking } \\
\text { - New thoughts from different people } \\
\text { from different parts of the world } \\
\text { - The interaction with my team members } \\
\text { and gaining knowledge from them } \\
\text { since their background was different } \\
\text { from mine. } \\
\text { Collaborative team learning. }\end{array}$ & $\begin{array}{l}\text { - } \text { CMC has increased my written skills. } \\
\text { - } \text { How we can work in a CMC team! } \\
\text { - } \text { It was a challenge. } \\
\text { - } \text { Professionalism is heightened. } \\
\text { - I got to try new technology. } \\
\text { - Sharing responsibilities. } \\
\text { - At least I can say I attempted a } \\
\text { computer-mediated team. } \\
\text { - It is very efficient and also increased } \\
\text { my communication skills. }\end{array}$ \\
\hline
\end{tabular}


Students who work in a team environment for the first time tend to revert to their previous skill sets where they are solely responsible for the final quality, scope, format, and structure of their work. In team environments, the emphasis shifts from individual contributions to achieving a group-consensus wherein one individual's ideas or approach may - or may not - be the solution selected by the group to complete the assigned tasks. This factor may cause some students (or other team members) to effectively withdraw from the group process.

In F2F team meetings, the behavior associated with a team member's tendency to withdraw from the group process is much easier to detect. Team leaders must be vigilant about the role each team member serves and work to insure that everyone on the team feels comfortable with their individual contributions as they relate to the overall goals and objectives of the team. Once this hurdle has been overcome, team performance can be predictably enhanced. If an individual's contributions are consistently overlooked and/or ignored by other members of the team, the tendency is for the "rejected" team members to isolate themselves from the team's efforts overall. Individual isolation/withdrawal and team accomplishments are polar opposites and must be avoided if the team is to succeed.

By giving team members an opportunity to assess their own - and their team member's participation and effectiveness during the team's project activities, students (or team members) are better able to answer the WIIFM question. When individuals feel empowered to provide honest feedback to the team leader or manager, they tend to display a higher level of commitment to the project activities and to their team members themselves. Figure 1 provides a sample template the authors have used in team-based projects to assess each team member's level of participation, commitment and effectiveness on semester-long project activities. It is important to note that the feedback received from each individual student is maintained in strict confidence between the individual student/team member and the faculty member. No one else is granted access to these confidential assessments. The end result of this mutual understanding of confidentiality is that students are more apt to convey their unabashed comments, thus giving the instructor (or manager) near real-time feedback into the group's overall performance. Furthermore, it may help identify any limitations or restrictions faced by the teams during the project. This provides the instructor or project leader an opportunity to improve the next project assignment as part of a continuous improvement initiative.

In a classroom setting, the results of these honest evaluations can be used to grade each team member's performance, as desired. This Peer Evaluation Process will help identify team members who carried more of the project load than their colleagues. It will also help identify those students or team members who did not participate in or contribute to the project as expected. These underperforming students or team members can then be identified more consistently, leading to appropriate grade adjustments. In a corporate setting these results could be used consistently and fairly to justify and award performance-based bonuses for team members. 


\section{Course Number - Course Title (e.g. ENGR 4335 - Workplace Safety and Ergonomics) \\ Peer Evaluation Form - $\underline{\text { Semester }} \underline{\text { Year }}$ (e.g. Spring 2014) \\ Group Name: \\ e.g. Brown Group}

Your Name:

Team Member's Name:

Team Member's Name:

Team Member's Name:
Points:

Points:

Points:

Points:

Your group was assigned a major semester project as an integral part of Course Number -

Course Title. Please provide me with your fair and honest evaluation of each team member's performance on the semester project. Assign a score to each team member (including yourself) according to the following criteria. You have been given 600 points to rate your group's performance this semester. You can use this number in any mix you see fit. For example, if there are three team members, you could give yourself 275 points, your first team member 175 points and the second team member 150 points for a total of 600 . Or you may assign 200 points to each member if each one participated equally in the combined effort.

ANY COMBINATION WHICH RESULTS IN A TOTAL OF 600 POINTS IS ACCEPTABLE!

Be fair and honest in your evaluation and provide specific written comments where you feel it is warranted.

1. Class Participation (attendance, effort, support, knowledge, attitude, etc.)

2. Outside Research/Data Collection Effort (participation, writing, support, etc.)

3. Project Support (research, writing, presentation, preparation, etc.)

4. Additional Comments (use additional sheets if needed):

Figure 1. Sample Template for Collecting Project Team Effectiveness Data (Jackson, 2005)7 


\section{Conclusion}

The primary question addressed in this paper was whether students that subscribe to the WII-FM (What's in it for me?) philosophy could still function as effective members of a team. In the studies cited by Gomez, Wu, \& Passerini, (2010) ${ }^{6}$ and Chaparro, et al. (2005) ${ }^{4}$, the answer appears to be yes. Students can function very well as a team, even when subscribing to the WIIFM philosophy. Students are able to meet the objectives of the team and still walk away from the projects with a newly developed understanding of the team learning process. In a classroom setting, it is very important, however, for instructors to realize that students who may have never experienced the team concept in a project setting must first be taught the various stages of team development and interactions. It is necessary for new team participants to have an understanding of how to handle each stage of the team development process and how to move the team forward in order to complete the objectives at hand.

In the referenced studies, many students noted that their team experiences increased their awareness of technological challenges and provided valuable experience for future job opportunities in industry (Chaparro, et al., 2005) ${ }^{4}$. Work performed in the United States and in most countries in the Western world has shifted to working with teams (Evans \& Lindsay, 2010) ${ }^{5}$. There is a continuing need to teach students about various team dynamics that they are likely to encounter in the workplace and techniques to improve team building skills - such as communication and group decision making - before they enter their respective discipline. Future research involving student teams who participate in $\mathrm{F} 2 \mathrm{~F}$ and/or DE course delivery methodologies should continue to examine both the performance and social aspects of group communication and project performance issues.

The authors have provided the reader with a Peer Evaluation Template that has been used in a classroom to capture honest comments about a student's team project experiences. These studentbased assessments can be used in defining student performance grades for the project if desired. The Peer Evaluation Template can be easily adapted for use in an industrial or business setting to help project managers motivate team members to enhance project outcomes through increased involvement in team activities, while simultaneously improving team dynamics and communication with team members and other stakeholders.

\section{References}

1. Barkley, B., \& Saylor, J. (2001). Customer-driven project management. New York, NY: McGraw -Hill.

2. Bonebright, D. A. (2010). 40 years of storming: A historical review of Tuckman's model of small group development. Human Resource Development International, 13(1), 111-120. doi:10.1080/13678861003589099 
3. Brodie, L. M. (2009). Eproblem-based learning: Problem-based learning using virtual teams. European Journal of Engineering Education, 34(6), 497-509.

4. Chaparro, B., Langrall, R., Malzahn, D., Mohler, B., Russell, M., \& Whitman, L. (2005). A comparison of group processes, performance, and satisfaction in face-to-face versus computer-mediated engineering student design teams. Journal of Engineering Education, 94(3), 327-333.

5. Evans, J., \& Lindsay, W. (2008). Managing for quality and performance excellence. Mason, OH: Thomson Higher Education.

6. Gomez, E., Wu, D., \& Passerini, K. (2010). Computer-supported team-based learning: The impact of motivation, enjoyment, and team contributions on learning outcomes. Computers and Education, 55(1), 378-390.

7. Jackson, A. E. (2005). Evaluating team performance: Should all team members receive similar benefits? Industrial Engineer Magazine. 37(3), 38-42.

8. Letassy, N., Fugate, S., Medina, M., Stroup, J., \& Britton, M. (2008). Using team-based learning in an endocrine module taught across two campuses. American Journal of Pharmaceutical Education, 72(5), 1-6. Article 103.

9. Muchinsky, P. (2006). Psychology applied to work (8th ed.). Belmont, CA: Thomas Higher Education.

10. Tuckman, B. (1965). Developmental sequence in small groups. Psychological Bulletin, 63, 384-399.

11. Tuckman, B., \& Jensen, M (1977). Stages of small-group development revisited. Group \& Organizational Studies, 2(4), 419.

12. Vik, G. (2001). Doing more to teach teamwork than telling students to sink or swim. Business Communication Quarterly, 64(4), 112-119. 